\title{
Produção e aplicação de um jogo digital como ferramenta pedagögica para o ensino de Geologia
}

\author{
Development and application OF a digital game as a Pedagogical toOL FOR Geology teaching \\ Luciana Freitas de Oliveira França ${ }^{1}$, Werica Karen de Souza Alcântara², Anderson David Almeida da Silva², Karollaine Fernandes de Lima² \\ 1 - Doutora em Geociências, Colegiado de Geografia, Universidade de Pernambuco, Campus Petrolina. Petrolina, Pe, Brasil \\ 2 - Discentes do Curso de licenciatura em Geografia pela Universidade de Pernambuco, Campus Petrolina. Petrolina, Pe, Brasil

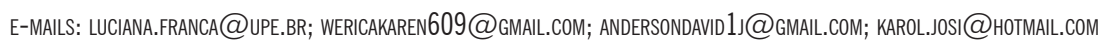

\begin{abstract}
This research brings the experience of the monitors in the discipline of General Geology with 23 students of the first period of the Geography course of the University of Pernambuco. This work sought to develop and apply a digital game that contemplates all the content of the subject, in order to facilitate the process of teaching and learning of students. The research method developed was explanatory descriptive, of quantitative and qualitative character. The Geological Quiz was produced based on a free platform, of low complexity, allowing a greater motivation of students in the learning process, through a playful and fun environment, where complex and abstract contents of Geology could be approached. However, although it is considered a positive and challenging tool for use in the classroom, it is still little used by teachers of various areas of knowledge.
\end{abstract}

Resumo: Esta pesquisa descreve a experiência vivenciada por monitores da disciplina Geologia Geral com 23 alunos do primeiro período do curso de Geografia da Universidade de Pernambuco, campus Petrolina. 0 trabalho objetivou desenvolver e aplicar um jogo digital que contemplasse todo o conteúdo da disciplina, com a finalidade de facilitar o processo de ensino e aprendizagem dos discentes. 0 método de investigação desenvolvido foi descritivo explicativo, de caráter quantitativo e qualitativo. Um Quiz Geológico foi produzido a partir de plataforma gratuita, de baixa complexidade, permitindo maior motivação dos alunos no processo de aprendizagem. 0 ambiente lúdico e divertido possibilitou abordar conteúdos complexos e abstratos da Geologia. No entanto, apesar de ser considerada uma ferramenta positiva e desafiadora para uso em sala de aula, o recurso ainda é pouco utilizado por professores de diversas áreas do conhecimento.
Citation/Citação: França, L. F. 0. Alcântara, W. K. S., Silva, A. D. A., \& Lima, K. F. (2020). Produção e aplicação de um jogo digital como ferramenta pedagógica para 0 ensino de Geologia. Terræ Didatica, 16, 1-7, e020040. doi: 10.20396/td.v16i0.8660015

Keywords: Didactic resources, Quiz, Learning, Geography.

Palavras-chave: Recursos didáticos, Questionários, Aprendizagem, Geografia.

Manuscript/Manuscrito:

Received/Recebido: 11/07/2020

Revised/Corrigido: 12/09/2020

Accepted/Aceito: 28/09/2020

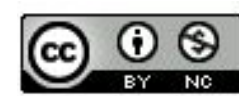

\section{Introdução}

A ciência geológica é de grande relevância para formação do professor de Geografia. A disciplina de Geologia Geral é a disciplina base para os estudos geográficos, já que discute sobre o sistema Terra, onde se desenvolve o espaço geográfico, objeto de estudo da Geografia. Apesar da relevância, os alunos de cursos de licenciatura em Geografia apresentam muitas dificuldades na compreensão dos termos técnicos inerentes à disciplina de Geologia e, em função de deficiências em leitura trazidas da educação básica, apresentam fragilidade na compreensão dos textos. Em muitos casos, os estudantes acabam não sentindo interesse pela disciplina, o que representa um grande obstáculo ao processo de aprendizagem (Fantinel, 2000).

(...) uma das reclamações generalizadas de escolas e universidades é de que os alunos não aguentam mais nossa forma de dar aula. Os alunos reclamam do tédio de ficar ouvindo um professor falando por horas [...]". (Moran, 2004. p.2).

Assim, é necessário se pensar em alternativas que possam sair do citado "tédio" e tentar inovar as aulas, por meio de uma aprendizagem ativa, utilizando diferentes ferramentas didáticas como suporte. Segundo Souza (2007), o recurso didático pode contribuir no desenvolvimento cognitivo dos alunos, possibilitando aprendizagem mais efetiva e marcante para toda a vida do discente. Dentre os diversos tipos de recursos didáticos, destacam-se os desenvolvidos a partir das tecnologias digitais. Silva \& Kalhil $(2018$, p.82) afirmam que a tecnologia digital se "coloca como uma linguagem que possibilita a interação, comunicação, e a expressão dos indivíduos por meio de diversos dispositivos computacionais conectados, ou não, à internet" 
possibilitando ser aplicada em diversas áreas do conhecimento, como no caso específico, para o ensino de Geologia. Neste contexto, este trabalho objetivou desenvolver e aplicar, em uma turma do $1^{\circ}$ período do curso de licenciatura em Geografia do Estado de Pernambuco, um jogo digital denominado Quiz Geológico, como forma de auxiliar o processo de aprendizagem dos conteúdos geológicos ministrados na disciplina Geologia Geral.

\section{Referencial Teórico}

As Tecnologias de Informação e Comunicação (TIC) estão cada vez mais presentes no cotidiano dos alunos. Essas tecnologias:

(...) tem como propósito de integrar os conteúdos abordados em aula com as tecnologias, que cada vez mais estão presentes na nossa sociedade, tais como o computador, internet, smartphone entre outros que unem o entretenimento com a aprendizagem (Marques \& Marques, 2016, p.1).

De acordo com o IBGE (2017), cerca de 74,9\% dos domicílios brasileiros possuem acesso ao telefone celular. E é por meio do celular que 98,7\% das pessoas acessam a internet. Entre as finalidades do acesso à internet, destacam-se o envio ou recebimento de mensagens de texto, voz ou imagens, alternativa indicada por $95,5 \%$ das pessoas. A popularização do uso do telefone celular está presente em diversos ambientes, inclusive na escola, o que nem sempre foi visto como algo benéfico para aprendizagem dos alunos (Rocha, 2015). Segundo Almeida (2015), os smartphones são verdadeiros computadores portáteis, com sistemas operacionais, hardwares e sensores que possibilitam a criação de diversos softwares e aplicativos (Apps). Os aplicativos são bastante utilizados para diversas funções, seja de caráter recreativo, ou para facilitar atividades diárias. No entanto, quando se fala da finalidade pedagógico dos celulares em salas de aula há bastante divergências entre os educadores.

De acordo com Pimenta \& Lopes (2017) a presença do celular em salas de aula tem sido motivo de muitas polêmicas entre os profissionais da educação. O cerne do problema, segundo os autores supracitados, estaria na funcionalidade do celular, que seria visto apenas como "um mero instrumento de distração para os estudantes" (Pimenta \& Lopes, 2017, p.53).

Nagumo (2014) destaca que o principal argumento dos professores sobre a proibição do uso dos celulares é que estes tirariam a atenção dos alunos e prejudicariam o andamento da aula. O autor afirma ainda que as leis e regimentos escolares seguem a mesma linha de controle e proibição do uso dos celulares. Contudo, alerta o autor, "a atenção do aluno não será alcançada apenas com a proibição do uso dos aparelhos, pois há diversas formas de passar o tempo sem prestar atenção no professor" (Negumo, 2014, p.69). É importante refletir sobre os benefícios e desafios do uso do celular na escola, ou mesmo no ambiente acadêmico. Embora a sociedade seja "simpatizante da tecnologia, não a define claramente como algo a ser considerado importante, mas a reconhece como uma incógnita a ser resolvida pela escola. Neste impasse, este aparato tecnológico estremece as bases mais conservadoras" (Reinaldo et al., 2016, p.78).

No entanto, é importante salientar que a utilização das tecnologias digitais em sala de aula ainda é "um grande desafio na escola, já que muitos educadores não cresceram dentro deste contexto e tem que se adaptar a esta nova realidade. Situação está que leva aos professores a ter receio em usufruir ferramentas computacionais dentro de sua prática pedagógica" (Mousquer \& Rolim, 2016, p.1). Por outro lado, segundo afirma Lèvy (1999, p. 34) “a questão central não está na mudança do ensino tradicional para os mediatizados por tecnologias, mas na transição de uma educação e uma formação estritamente institucionalizada para uma situação de troca de saberes".

Sancho \& Hernández (2006, p. 18) afirmam que "as tecnologias da informação e comunicação estão aí e ficarão por muito tempo, estão transformando o mundo e deve-se considerá-las no terreno da educação". No entanto, convém observar "que a mera adoção de tecnologias em sala de aula, de forma geral, não soluciona as dificuldades que encontramos no ensino" (Perez, Viali \& Lahm, 2015, p.155). É importante que haja uma mudança na própria dinâmica na sala de aula, não mais focada no professor, mas centralizada no aluno, possibilitando uma aprendizagem ativa (Piaget, 1983, Freire, 2001, Ausubel, 2003).

Tarouco et al. (2004, p.1) afirmam que o uso dos recursos tecnológicos na educação teria sido impulsionado a partir do rompimento com o "paradigma tradicional e surgimento do construtivismo, que enfatiza a participação e experimentação do sujeito na construção de seu próprio conhecimento, através de suas interações". Segundo Leivas \& Gobbi (2014), a escola teria papel principal de utilizar os 
recursos tecnológicos nas atividades pedagógicas dos estudantes, já que esses recursos fazem parte do cotidiano dos alunos, na tentativa de tornar a aprendizagem mais significativa, diminuindo a distância entre o aluno e a escola.

De acordo com Santos \& Leite (2019, p.194) os Recursos Didáticos Digitais (RDD) "surgem cada vez mais associados aos dispositivos móveis (DM), em sua grande maioria são apresentados na forma de aplicativos (Apps) para tablets e smartphones" e contribuem para se pensar em estratégias para melhoria do processo de aprendizagem dos alunos, por meio de aplicativos que abordam determinados conteúdos, propostos pelo docente. Dentre as diversas finalidades desenvolvidas pelos Apps, destaca-se a produção de games. De acordo com Prensky (2003) os modernos jogos de computador oferecem oportunidades de aprendizado a cada segundo, ou fração de segundo.

Eles podem ser reconhecidos como facilitadores da aprendizagem de assuntos complexos e por desenvolver importantes habilidades cognitivas, como a resolução de problemas, a percepção, a criatividade e o raciocínio rápido (Santos \& Leite, 2019, p.194)

Segundo Tarouco et al. (2004) há uma grande diversidade de jogos com o objetivo de ensinar conceitos complexos e abstratos, como definição de eletrização, conservação de energia, trigonometria, entre outros. No entanto, o maior desafio está em não deixar que o aluno desvie sua atenção quanto ao objetivo principal do jogo educacional, que é a aprendizagem, deixando para trás os conceitos que precisam ser desenvolvidos e internalizados pelos estudantes. A criação de jogos não se restringe aos profissionais que dominam técnicas de programação. Há diversos softwares de fácil aplicação disponíveis na internet, intuitivos e com baixo grau de complexidade, podendo ser desenvolvidos pelos próprios professores, mesmo com pouca experiência em programação (Santos \& Leite, 2019).

O Quiz Game é um jogo digital que pode ser utilizado em salas de aula para envolver os alunos no conteúdo ministrado de forma interativa. Nesta modalidade, é possível adicionar perguntas sobre conteúdo da disciplina e estas são convertidas em um "jogo de pontuação, interação e ranqueamento" (Dellos, 2015, Sande \& Sande, 2018). Quando se avaliam os Apps na área da Geologia, observam-se inúmeros aplicativos disponíveis na loja virtual Google Play, com destaque para aplicativos de Geo- logia Estrutural, Paleontologia, Rochas, Minerais, dentre outros. Todos podem ser instalados em smartphones com sistema operacional Android. A grande maioria traz apenas informações do conteúdo ou vídeo aulas, possibilitando pouca interatividade entre os alunos, que precisam conectados à Internet. Outra questão que merece ser ressaltada é que a grande maioria dos aplicativos está na língua inglesa. Além disso, os que oferecem maior interatividade e simulações são pagos. Daí vem o interesse na produção de um jogo simples e gratuito, que possibilite a abordagem dos assuntos de Geologia.

\section{Materiais e Métodos}

Esta pesquisa descreve a experiência vivenciada por monitores da disciplina Geologia Geral com vinte e três alunos do primeiro período do curso de Geografia da Universidade de Pernambuco, campus Petrolina. A pesquisa é do tipo descritiva explicativa, de caráter quantitativo e qualitativo, e tem como procedimentos metodológicos as seguintes etapas:

- Revisão Bibliográfica: Nesta fase foi realizado o levantamento bibliográfico sobre metodologias ativas, jogos digitais didáticos, com ênfase aos utilizados para os estudos sobre Geologia, além das principais referências sobre conteúdos geológicos;

- Elaboração do questionário: Nesta etapa foram desenvolvidas seis questões de múltipla escolha e uma questão aberta para se avaliar a percepção dos alunos quanto ao uso do Quiz Geológico na disciplina de Geologia Geral. Na Tabela 1 podem ser observadas as questões aplicadas para os discentes.

Tabela 1. Questionário sobre o uso do Quiz Geológico Como você classificaria a experiência da técnica do Quiz Geológico na disciplina da Geologia ?

Quais os pontos positivos do uso do Quiz?

Quais os pontos negativos do uso do Quiz?

Você utilizaria essa técnica do Quiz com alunos da educação básica?

Algum professor seu de educação básica já utilizou o Quiz em sala de aula para avaliação da aprendizagem ?

Você gostaria de ver o uso do Quiz em outras disciplinas?

Quais os pontos que precisam melhorar na técnica do Quiz utilizado na disciplina de Geologia Geral? 
- Produção do jogo digital: O jogo foi produzido na plataforma GoConqr de jogos educacionais. A escolha da plataforma foi feita por ser gratuita e de baixo grau de complexidade (Santos \& Leite, 2019). Na plataforma foram adicionadas quarenta questões de múltipla escolha, com quatro ou cinco opções de alternativas e com intervalo de vinte segundos para cada resposta. As questões versavam sobre Geologia Geral, referente ao universo, estrutura interna da Terra, carta cronoestratigráfica, tectônica de placas, minerais e rochas, estratigrafia, paleontologia e Geologia do Brasil. As questões eram convertidas em um "jogo de pontuação, interação e ranqueamento" (Dellos, 2015, Sande \& Sande, 2018);

- Aplicação do Jogo: Após a elaboração do Quiz, o link foi enviado para o grupo do WhatsApp da turma do primeiro período de Geografia e finalmente os alunos puderem utilizar individualmente o jogo didático sobre Geologia.

- Aplicação do questionário: Após a aplicação do jogo foi entregue aos vinte e três alunos do curso que participaram da atividade o questionário de avaliação do Quiz.

- Tabulação e avaliação dos dados: Por fim, os dados foram tabulados no Software Microsoft Excel ${ }^{\circledR}$ e foram gerados gráficos, que posteriormente foram submetidos a interpretação.

\section{Resultados e Discussão}

\section{Elaboração e aplicação do Quiz Geológico}

Ojogo digital do Quiz Geológico foi produzido por meio da plataforma GoConqr, disponível no site https://www.goconqr.com. A plataforma contém recursos educacionais digitais gratuitos e de baixa complexidade. A criação do Quiz na plataforma foi bastante simples e intuitiva. O procedimento inicial foi clicar no ícone "criar um Quiz" (Fig.1 A), e posteriormente inserir as perguntas e respostas, delimitando o tempo de respostas pontuação das perguntas do jogo (Fig. 1B), e por fim a pontuação final obtida pelo jogador, disponibilizando todas as respostas corretas e incorretas (Fig.1C).

$\mathrm{Na}$ tela final do jogo é possível observar algumas informações do Quiz, a saber: o percentual de acerto, o tempo executado no jogo, os pontos obtidos nas questões, as respostas corretas e incorretas (Fig. 1C). Uma vez elaborado, o jogo foi aplicado na turma do primeiro período do curso de Licenciatura em Geografia. A aplicação ocorreu nas últimas aulas da disciplina como forma de fazer uma revisão

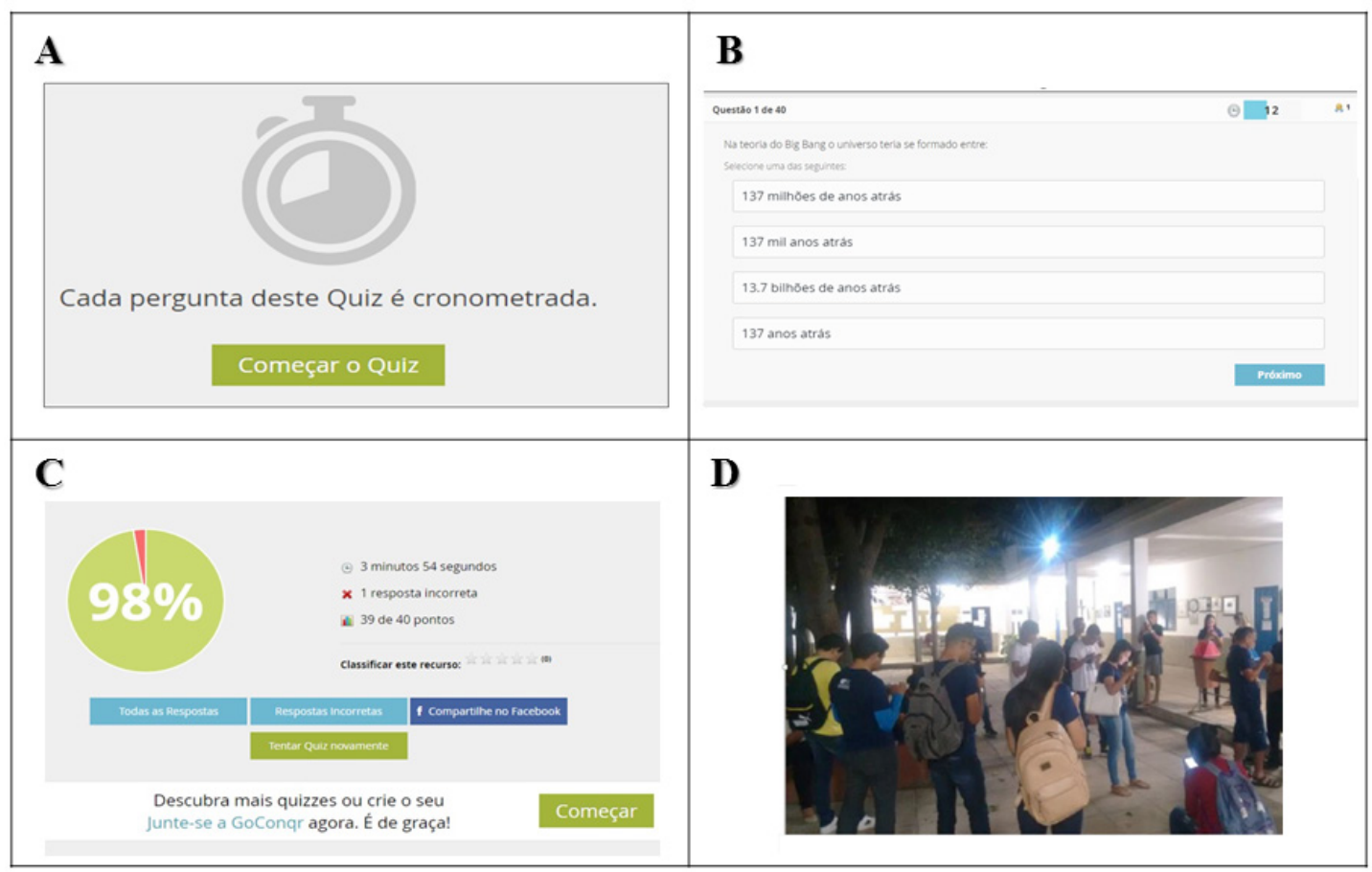

Figura 1. Aspectos da aplicação prática do Quiz Geológico: Painel inicial (A). Imagem das questões, alternativas e do tempo (na parte superior da tela) do Quiz Geológico (B). Imagem da tela final do Jogo (C). Alunos da turma de licenciatura em Geografia atentos ao Quiz Geológico (D)

\begin{tabular}{c|c|c|c|c|c|}
\hline (C) Terrae Didat. & Campinas, SP & v.16 & $1-7$ & $\mathrm{e} 020040$ & 2020 \\
\hline
\end{tabular}


geral do conteúdo de toda a disciplina, e avaliar o conhecimento que os alunos adquiriram ao longo do semestre letivo (Fig. 1D).

O Quiz foi aplicado no pátio da unidade de ensino, local com melhor acesso à rede pública sem fio. Durante a aplicação do jogo foi notório o interesse dos estudantes, que concorriam entre si para um melhor desempenho. A maioria dos alunos teve um percentual de acerto entorno de $68 \%$. O aluno vencedor acertou $90 \%$ das questões, recebendo um brinde pela vitória. Após a finalização do jogo, foi entregue um questionário aos alunos para que eles avaliassem o Quiz Geológico que haviam utilizado.

\section{Análise do uso do Quiz Geológico}

Inicialmente os alunos foram questionados sobre como classificariam o uso do Quiz Game na disciplina de Geologia Geral. De acordo com a Figura 2A, cerca de $92 \%$ dos alunos consideraram a experiência do jogo como uma experiência positiva no processo de aprendizagem dos conteúdos geológicos, e apenas $8 \%$ dos alunos avaliaram o uso do Quiz como irregular ou insuficiente.

Foram avaliados também os pontos positivos da técnica. 39\% indicaram que a técnica criou um ambiente descontraído para avaliar o conhecimento aprendido ao longo das aulas. Por outro lado 25\% sugeriram que a técnica levou a uma quebra da aula tradicional. Cerca de 19\% dos alunos indicaram que o uso do Quiz possibilitou uma revisão dos conteúdos trabalhados em sala e $17 \%$ sentiram-se motivados com o uso da técnica (Fig. 2B).

Quanto aos pontos negativos do uso do Quiz, conforme a Figura 2C, cerca de $66 \%$ dos alunos indicaram que a escolha do tempo de 20 segundos para responder as questões do Quiz foi muito curta. Por outro lado, $16 \%$ dos alunos pontuaram que o número de quarenta questões utilizados para o jogo foi muito alto. $6 \%$ também indicaram ter tido dificuldade em compreender o que era solicitado nas questões, e ainda $6 \%$ não viram contribuição do jogo com a fixação do conteúdo da disciplina. Por fim, apenas $6 \%$ declaram que não houve pontos negativos.

Foi analisado também se os alunos do curso de Geografia utilizariam a técnica do Quiz com os seus futuros alunos da educação básica. Neste quesito, de acordo com a Figura 2D a grande maioria dos alunos, cerca de $91 \%$ afirmaram que usariam a técnica com seus futuros alunos. Além disto, foi analisado a experiência que os alunos tiveram na

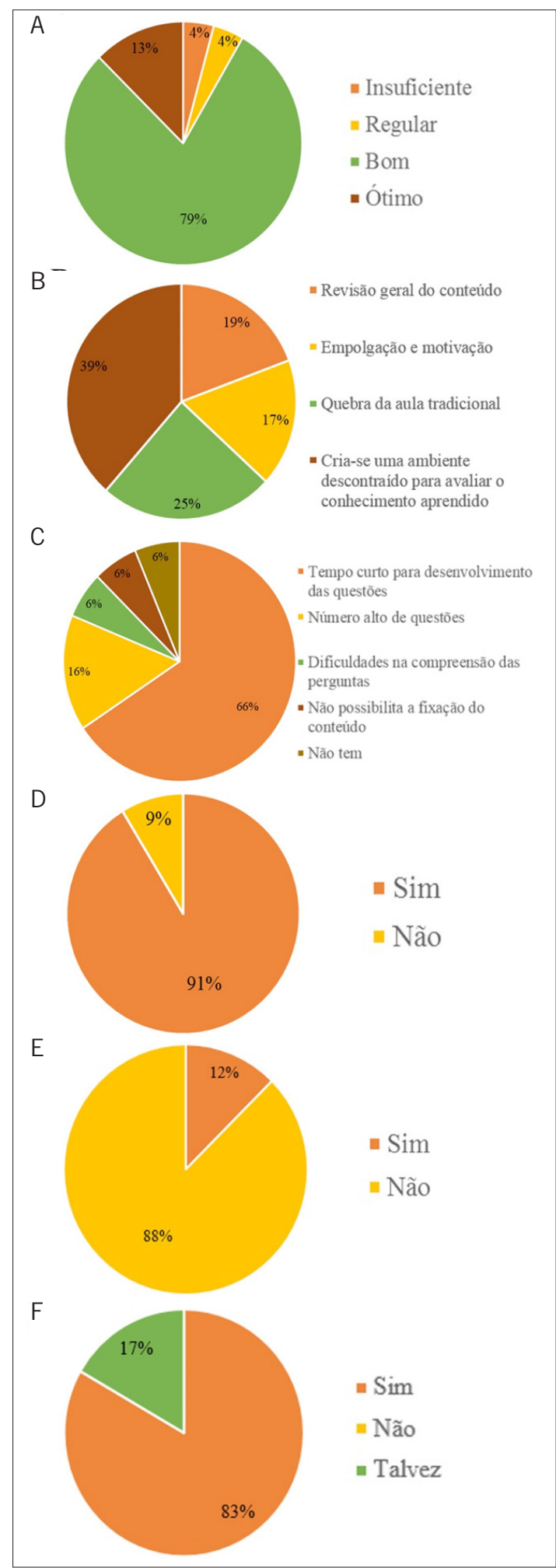

Figura 2. Avaliação dos alunos quanto ao uso do Quiz Game (A). Pontos positivos avaliados do Quiz Game (B). Pontos negativos avaliados sobre a técnica do Quiz Game (C). Possibilidade de uso do Quiz Game na educação básica (D). Participação dos alunos com o Quiz Game na educação básica (E). Uso do Quiz Game em outras disciplinas (F) 
educação básica. Conforme a Figura 2E, cerca de $88 \%$ dos alunos afirmaram que durante a educação básica essa técnica nunca foi utilizada, e apenas 12\% tiveram essa experiência do Quiz como ferramenta de avaliação da aprendizagem.

De acordo com Moran (2014, p.51) "a chegada das tecnologias móveis à sala de aula traz tensões, novas possiblidades e grandes desafios". Nem sempre os professores são favoráveis ao uso dessas tecnologias móveis em sala de aula, como foi observado na Figura 2E, seja pela pouca habilidade docente com essas ferramentas digitais, ou por acreditar que a mesma funcionaria apenas como distração para os alunos, não contribuindo no processo de aprendizagem dos mesmos (Mousquer \& Rolim, 2016; Pimenta \& Lopes, 2017).

Quando questionados sobre o uso do Quiz em outras disciplinas do curso, segundo a Figura 2F, praticamente $100 \%$ dos alunos gostariam de ver o jogo digital em outras disciplinas do curso de Geografia. Isso mostra a necessidade do professor repensar o uso de recursos didáticos digitais em suas aulas, já que essas tecnologias estão no cotidiano do aluno, e podem ser utilizadas como ferramentas didáticas para melhoria da aprendizagem.

Por fim, os discentes foram indagados sobre a seguinte questão: Quais os pontos que precisam melhorar na aplicação da técnica do Quiz para a disciplina de Geologia Geral? De modo similar aos resultados da Figura 2C, a maioria ratificou a necessidade de se ampliar o tempo de resposta das questões. Outro ponto questionado pelos alunos foi o baixo suporte oferecido, no momento da aplicação, pela rede de internet da universidade para atividades dessa natureza. Assim, é necessário que as instituições de ensino ofereçam a infraestrutura necessária para aplicação destas atividades.

\section{Considerações Finais}

As tecnologias digitais, muito presente no cotidiano dos alunos, estão também presentes nas escolas e nas universidades, pelo uso de diversas ferramentas, entre elas os jogos didáticos e os simuladores de experimentos, que são considerados recursos didáticos, desde que sejam adaptados aos conteúdos científicos trabalhados no ambiente acadêmico. As ferramentas digitais tiram o aluno da condição de ouvinte e o elevam à categoria de agente ativo em seu próprio processo de aprendizagem. A utilização de recursos didáticos digitais, como smartphones relacionados a games, como o
Quiz, podem propiciar experiências positivas no processo de ensino e aprendizagem, já que motivam os alunos para melhor desempenhar suas atividades acadêmicas ou escolares.

O Quiz Geológico foi produzido a partir de uma plataforma gratuita, de baixo grau de complexidade, bastante intuitiva e que pode ser utilizada por docentes que não tenham conhecimento de linguagem de programação ou com pouca habilidade em ferramentas digitais, possibilitando experiências com recursos didáticos muito solicitados pelos alunos.

As contribuições do Quiz Geológico foram inúmeras, sobretudo em relação à motivação dos alunos no processo de aprendizagem, por meio de um ambiente lúdico e divertido, no qual foi possível abordar conteúdos complexos, e muitas vezes exaustivos, de forma inovadora. No entanto, apesar de ser considerada uma ferramenta positiva e desafiadora para ser usada na sala de aula, o recurso ainda é pouco utilizado pelos professores de diversas áreas do conhecimento.

\section{Agradecimentos}

Os autores agradecem à Pró-Reitoria de Graduação da Universidade de Pernambuco (PROGRAD/ UPE), por intermédio da Coordenação de Assuntos Estudantis (CAE), no Programa de Fortalecimento Acadêmico (PFA) pela concessão da bolsa de monitoria para o desenvolvimento da pesquisa.

\section{Referências}

Almeida, A. A. (2015). Contribuição para o estudo do uso de aplicativos de smartphone no ensino de Física. Niterói: Universidade Federal Fluminense. 57p. (Trab. Concl. Curso).

Ausubel, D. P. (2003). Aquisição e Retenção de Conhecimentos: Uma Perspectiva Cognitiva. Lisboa: Plátano.

Bock, A. M. B., Furtado, O., \& Teixeira, M. L T. (2009). Psicologias: uma introdução ao estudo da Psicologia. 14 ed. São Paulo: Saraiva. 368p.

Costa, C. M. (2018). Quiz computacional: elaboração, aplicação e avaliação de um recurso didático tecnológico como ferramenta de ensino/aprendizagem. Niterói: Universidade Federal Fluminense. 151 p. (Dissert. Mestr. Ciências da Natureza).

Dellos, R. (2015). Kahoot! A digital game resource for learning. International Journal of Instructional Technology and Distance Learning, 12(4). 49-52. URL: http://www.itdl.org/Journal/Apr_15/Apr15. pdf. Acesso 10.10. 2019

Fantinel, L.M. (2000) Práticas de Campo em Geologia In- 
trodutória: papel das atividades de campo no ensino de Fundamentos de Geologia do curso de Geografia, Universidade Federal de Minas Gerais (UFMG). Campinas: Instituto de Geociências, Universidade Estadual de Campinas. (Dissert. Mestr. Geociências).

Freire, P. (2001). Pedagogia da Autonomia: saberes necessários à prática educativa. São Paulo: Paz e Terra. 76 p.

Instituto Brasileiro de Geografia e Estatística (IBGE). (2017) Acesso à Internet e a televisão e posse de telefone móvel celular para uso pessoal. Rio de Janeiro: IBGE. URL: https://biblioteca.ibge.gov.br/visualizacao/livros/liv101631_informativo.pdf. Acesso 30.09.2019.

Leivas, J., Gobbi, J. (2014) O software GeoGeabra e a engenharia didática no estudo de áreas e perímetros de figuras planas. Revista Brasileira de Ensino de Ciência e Tecnologia, 7(1), 182-199. doi: 10.3895/ S1982-873X2014000100010.

Lèvy, P. (1999) Cibercultura. São Paulo: Editora 34. 260 p.

Lopes, P. A., Pimenta, C. C. C. (2017). O uso do celular em sala de aula como ferramenta pedagógica: benefícios e desafios. Revista Cadernos de Estudos e Pesquisa na Educação Básica, 3(1), 52-66. URL: https:// periodicos.ufpe.br/revistas/cadernoscap/article/ view/229430/28802. Acesso 02.10.2019

Marques, J. F. Z, Marques, K. C. D. A. (2016) utilização de aplicativos por meio de smartphone como possibilidades para o Ensino de Química. In: Anais do XVIII ENEQ, Santa Catarina. p. 1-11. URL: http://www. eneq2016.ufsc.br/anais/resumos/R0013-1.pdf Acesso 05.09.2019,

Mousquer, T., Rolim, C. O. (2016). A utilização de dispositivos móveis como ferramenta pedagógica colaborativa na Educação Infantil. In: Anais do II Simpósio da Tecnologia da Informação. Santo Ângelo, 2011. URL: http:/www.santoangelo.uri.br/stin/Stin/trabalhos/11.pdf. Acesso 22.11.2019

Nagumo, E. (2014). O uso do aparelho celular dos estudantes na escola. Brasília: Universidade de Brasília. (Dissert. Mestr. Educação). 11p.

Perez, M. C., Viali, L., Lahm, R. A. (2016). Aplicativos para tablets e smartphones no ensino de Física. Ciências \& Ideias, 7(1), 155-173. URL: https://revistascientificas.ifrj.edu.br/revista/index.php/reci/ article/view/426/363. Acesso 26.09.2020.

Piaget, J. A. (1983). Epistemologia genética; Sabedoria e ilusões da filosofia; Problemas de psicologia genética. 2 ed. São Paulo: Abril Cultural (Coleção Os pensadores). 294 p.

Prensky, M. (2003). Digital game-based learning. Computers in Entertainment (CIE), 1(1), 21-21. URL: https://marcprensky.com/writing/Prensky\%20-\%20 Ch1-Digital\%20Game-Based\%20Learning.pdf. Acesso 30.10.2019.

Reinaldo, F., Magalhães, D. R., Reis, L. P., Gaffuri, S., Freddo, A., \& Hallal, R. (2016). Impasse aos desafios do uso de smartphones em sala de aula: investigação por grupos focais. Revista Ibérica de Sistemas e Tecnologias de Informação, (19), 77-92. doi: http:// dx.doi.org/10.17013/risti.19.77-92.

Rocha, R. S. (2015). O uso do celular como ferramenta pedagógica: repercussões na aprendizagem de Ciências a partir da produção de vídeos. Porto Alegre: Universidade Federal do Rio Grande do Sul. 58p. (Trab. Concl. Curso Especialização).

Tarouco, L. M. R., Roland, L. C., Fabre, M. C. J. M., Konrath, M. L. P. (2004). Jogos educacionais. Renote, 2(1), 1-7. doi: 10.22456/1679-1916.13719.

Sancho, J. M., \& Hernández, F. (2006). Tecnologias para transformar a educação. Porto Alegre: Artmed. 200 p.

Sande, D, Sande, D. (2018). Uso do kahoot como ferramenta de avaliação e ensino-aprendizagem no ensino de microbiologia industrial. Holos, 34(1), 170-179. doi: 10.15628/holos.2018.6300.

Santos, C.E.M., Leite, B.S. (2019). Construção de um jogo educativo em uma plataforma de desenvolvimento de jogos e aplicativos de baixo grau de complexidade: o caso do Quizmica. Radioatividade, 17(1), 193-202. doi: 10.22456/1679-1916.95725.

Silva, W. A., Kalhil, J. B. (2018). Tecnologias digitais no ensino de ciências: reflexões e possibilidades na construção do conhecimento científico digital. Revista Brasileira de Educação em Ciências e Educação Matemática, 2(1), 77-91. doi: 10.33238/ReBECEM.2018.v.2.n.1.19155.

Souza, S. E. (2007). O uso de recursos didáticos no ensino escolar. In: I Encontro de Pesquisa em Educação, IV Jornada de Prática de Ensino, XIII Semana de Pedagogia da UEM: "Infância e Praticas Educativas". Maringá, PR. p.110-114. URL: http://www.dma. ufv.br/downloads/MAT\%20103/2015-II/slides/ Rec\%20Didaticos\%20-\%20MAT\%20103\%20 -\%202015-II.pdf. Acesso 22.11.2019 